\title{
Training with robot-applied resistance in people with motor-incomplete spinal cord injury: Pilot study
}

\author{
Tania Lam, PhD; ${ }^{1-2^{*}}$ Katherine Pauhl, MSc; ${ }^{1-2}$ Amanda Ferguson, BScPT; ${ }^{3}$ Raza N. Malik, BKin; ${ }^{1-2}$ Andrei \\ Krassioukov, MD, PhD; ${ }^{2,4-5}$ Janice J. Eng, $\mathbf{P h D}^{2,5-6}$ \\ ${ }^{1}$ School of Kinesiology and ${ }^{2}$ International Collaboration on Repair Discoveries, University of British Columbia, \\ Vancouver, British Columbia, Canada; ${ }^{3}$ NeuroMotion Physical Therapy, Vancouver, British Columbia, Canada; \\ ${ }^{4}$ Department of Medicine, Division of Physical Medicine and Rehabilitation, University of British Columbia, Vancouver, \\ British Columbia, Canada; ${ }^{5}$ GF Strong Rehabilitation Centre, Vancouver, British Columbia, Canada ${ }^{6}$ Department of \\ Physical Therapy, University of British Columbia, Vancouver, British Columbia, Canada
}

\begin{abstract}
People with motor-incomplete spinal cord injury (m-iSCI) can recover basic walking function but still have difficulty performing the skilled walking required for everyday environments. We hypothesized that a robotic-based gait rehabilitation strategy founded on principles of motor learning would be a feasible and potentially effective approach for improving skilled walking in people with $\mathrm{m}$-iSCI. Fifteen individuals with chronic ( $>1 \mathrm{yr}$ ) $\mathrm{m}$-iSCI were randomly allocated to body weight-supported treadmill training (BWSTT) with Lokomat-applied resistance (Loko-R) or conventional Lokomat-assisted BWSTT (Control). Training sessions were $45 \mathrm{~min}, 3$ times/week for $3 \mathrm{mo}$. Tolerance to training was assessed by ratings of perceived exertion and reports of pain/ soreness. Overground skilled walking capacity (Spinal Cord Injury-Functional Ambulation Profile [SCI-FAP]), as well as walking speed and distance, were measured at baseline, posttraining, and 1 and 6 mo follow-up. Our results indicate that Loko-R training could be feasibly applied for people with miSCI, although participants in Loko-R tended to report higher levels of perceived exertion during training. Participants in the Loko-R group performed significantly better in the SCI-FAP than Control at posttraining and in follow-up assessments. This study provides evidence that Loko-R training is feasible in people with m-iSCI. Furthermore, there is preliminary evidence suggesting that Loko-R may help improve performance in skilled overground walking tasks.
\end{abstract}

Clinical Trial Registration: ClinicalTrials.gov; NCT00610974. "Enhancing Walking in People With Incomplete Spinal Cord Injury: a Pilot Study"; https://clinicaltrials.gov/ct2/show/ NCT00610974

Key words: body weight support, functional ambulation, gait training, Lokomat resistance, motor-incomplete SCI, motor learning, robotics, skilled walking, spinal cord injury.

\footnotetext{
Abbreviations: $6 \mathrm{MWT}=6 \mathrm{~min}$ walk test, $10 \mathrm{MWT}=10 \mathrm{~m}$ walk test, AIS = American Spinal Injury Association Impairment Scale, ANCOVA = analysis of covariance, ANOVA = analysis of variance, BWS = body weight support, BWSTT = body weight-supported treadmill training, $\mathrm{CI}=$ confidence interval, Loko-R = Lokomat-applied resistance, MDC95 = 95 percent minimal detectable change, $\mathrm{m}$-iSCI $=$ motorincomplete spinal cord injury, $\mathrm{MVC}=$ maximum voluntary contraction, $\mathrm{RPE}=$ rating of perceived exertion, $\mathrm{SCI}=$ spinal cord injury, SCI-FAP = Spinal Cord Injury-Functional Ambulation Profile, $\mathrm{SD}=$ standard deviation.

*Address all correspondence to Tania Lam, PhD; Human Locomotion Research Laboratory, Blusson Spinal Cord Centre, 818 West 10th Ave, Vancouver, BC V5Z 1M9, Canada; 604-675-8807; fax: 604-675-8820.
}

Email: tania.lam@ubc.ca http://dx.doi.org/10.1682/JRRD.2014.03.0090 


\section{INTRODUCTION}

It is estimated that almost half of all people with spinal cord injury (SCI) have motor-incomplete injuries (American Spinal Injury Association Impairment Scale [AIS] C or D) [1-2], meaning that there is some preservation of voluntary motor function below the level of injury. It is possible for people with motor-incomplete SCI (m-iSCI) to recover basic walking function, especially with intensive, task-specific gait training [3]. Body weight-supported treadmill training (BWSTT) is one such approach that has garnered intense interest over the years as a promising rehabilitation intervention to promote the recovery of walking in people with motorincomplete SCI [4]. This has even led to the development of robotic devices, such as the Lokomat (Hocoma AG; Volketswil, Switzerland) [5], to facilitate the implementation of BWSTT. The key principles of BWSTT have included the provision of partial body weight support (BWS) through a harness system so that the person bears as much weight as possible and the repetitive cycling of the leg through gait motions, which is enabled by the treadmill and assisted by therapists or robotic devices [68]. The provision of relevant locomotor-related sensory cues and the resulting motor activity elicited through this type of task-specific training is thought to underlie functional retraining and reorganization of the nervous system $[3,9]$.

However, the scientific evidence so far suggests that BWSTT is not better than overground gait training in people with SCI [4]. In the largest clinical trial in SCI gait rehabilitation to date, individuals with subacute $\mathrm{m}$-iSCI who underwent BWSTT had equivalent outcomes in functional walking capacity as those who underwent the same intensity of overground gait training [10-11]. Although there was some debate as to whether the overground training used in this clinical trial was reflective of a realistic "conventional" therapy [12-13], the results were consistent with the concept that intensive practice and task-oriented gait retraining (whether it is provided by BWSTT or overground practice) can improve walking outcomes.

For people with chronic $(>12 \mathrm{mo}) \mathrm{SCI}$, it is still unclear what specific gait training modality provides the best outcomes. There is evidence that manually assisted BWSTT can significantly improve functional balance and ambulation [14]. Others have also shown better outcomes in walking speed and distance as well as in the quality of gait kinematic patterns in people who underwent BWSTT than in those who received overground gait training [15]. However, recent results from one of the largest randomized controlled studies in gait rehabilitation for chronic SCI to date have shed some doubt on the superiority of this approach. Field-Fote and Roach found that overground training combined with functional electrical stimulation (FES) to the ankle dorsiflexor muscles was superior to BWSTT, BWSTT with FES, and robot (Lokomat)-assisted treadmill training [16]. Indeed, the introduction of robotics technology for gait rehabilitation, intended to facilitate the delivery of intensive, taskoriented gait training, has raised even more questions about the clinical utility of expensive technology in rehabilitation. A review of clinical studies on the effectiveness of robotic training devices in SCI concluded that robot-assisted gait training is no better than other gait training modalities [17]. Studies of robot-assisted gait training in other neurological populations have reached similar conclusions [18-19].

So far, it appears that BWSTT and robot-assisted gait training have fallen short of their promise [20]. One possibility is that these training modalities do not provide adequate challenge to drive motor learning. It is known that sensory input is a key modulator of locomotor output [21], and indeed, this concept formed the basis for the promise of task-specific locomotor training (such as that provided by BWSTT) for improving walking following neurological injury [3]. Sustained alterations in the movement environment can also mediate longer-term locomotor adaptations via feedback-error learning (recalibration of motor commands based on changes in sensory feedback) [22-23]. Several studies have shown that sustained (several minutes) exposure to forces that resist lower-limb flexion during walking (e.g., using robotic devices or attaching weights around the leg) lead to changes in the locomotor command that are revealed in the aftereffects (e.g., high stepping) that are observed as soon as the forces are removed [24-29]. The presence of aftereffects suggests the formation of anticipatory locomotor commands in response to the resistance and is an example of how feedback-error learning can be used to enable locomotor adaptations. Feedback-error learning during walking can be used to elicit locomotor adaptations in individuals with m-iSCI [30-32]. Following short-term adaptation to a robot-applied resistance against hip flexion, aftereffects in the form of a longer stride length are observed [30,32]. These aftereffects 
persist even when subjects step overground immediately after walking against resistance [32].

These results raise interesting possibilities for the design of new gait rehabilitation strategies for people with m-iSCI. Recent studies have provided some indication for the potential benefits of a training program based on strategies that can elicit locomotor adaptations based on feedback-error learning. Using a crossover design, Wu et al. compared robot-applied resistance versus assistance over an 8 wk BWSTT program [33]. Significant increases in overground walking speed were observed following training, but no differences were found between resistance and assistance training [33]. Given that resistance training enables specific aftereffects in the dynamic control of the swing phase [24-29], it is possible that simple tests of overground walking speed may not adequately capture the particular advantages of this approach to locomotor training, i.e., walking tasks where the dynamic control of leg flexion is particularly important (such as stepping over an obstacle).

In people with $\mathrm{m}$-iSCI, diminished hip, knee, and/or ankle flexion are commonly observed during swing, compromising foot clearance height [34-36]. Such impairments likely also contribute to deficits in the ability to adapt to the demands of skilled walking tasks, such as walking up slopes [37] or crossing obstacles [38]. Given these functional considerations, it seems warranted to further investigate the potential benefits of gait training combined with resistance. In people with chronic stroke, we have shown that up to 12 wk of BWSTT combined with leg weights around the paretic limb could improve functional ambulation, including the ability to climb stairs [39]. A recent case report study of the effect of a 3 mo training study using Lokomat-applied resistance in an individual with chronic m-iSCI also showed very promising results [40]. Improvements were noted not only in overground walking speed and distance but also in skilled walking tasks, such as obstacle crossing and stair climbing, as well as the kinematic quality of the gait pattern [40]. The results from these studies are encouraging, but controlled studies are required to understand the potential benefits of resistance training combined with BWSTT. Therefore, the purpose of this pilot study was to determine the feasibility and evaluate the potential efficacy of Lokomat-applied resistance (Loko-R) training on functional ambulation, especially skilled overground walking, in people with chronic m-iSCI.

\section{METHODS}

\section{Participants}

Individuals with m-iSCI (AIS C or D) were invited to participate in this study. Participants were required to have, at minimum, the ability to walk on a treadmill with BWS but without manual assistance. The inclusion criteria were (1) m-iSCI at least $1 \mathrm{yr}$ ago and (2) 19 to $65 \mathrm{yr}$ old. The exclusion criteria were (1) lesion level below thoracic 11 or lower motoneuron injury; (2) inability to step even with the help of a treadmill and partial BWS; (3) weight $>300 \mathrm{lb}$ or height $>6 \mathrm{ft} 1$ in. (size limitations of Lokomat); (4) presence of cardiac, musculoskeletal, or other condition for which exercise is contra-indicated; and (5) participation in rehabilitation therapy or other research study with exercise or mobility outcomes. All participants provided written informed consent and all procedures were approved by the University of British Columbia Clinical Research Ethics Board.

\section{Study Design}

We employed a double-blind, stratified, randomized controlled trial design to compare BWSTT with custom software control of the Lokomat to apply resistance against the hip and knee (Loko-R) [26,40] versus conventional Lokomat-assisted BWSTT (Control) [8,41-42]. Participants were not informed about the specific purpose or hypothesis of the study; they were told only that the amount of assistance provided by the Lokomat would differ between the two groups. None of the participants had prior experience with Lokomat training. A blinded assessor (A.F.) assessed all outcome measures, which were recorded at baseline, posttraining, and 1 and 6 mo follow-up.

Participants were screened for eligibility prior to determining their group allocation. They were then stratified according to the Wheeled Mobility Scale [43]. Participants were asked to report which category of the Wheeled Mobility Scale applied to them and were stratified based on a score of 5 or above (denoting the ability to walk, at minimum, for exercise at home). They were then randomized to either Loko-R or Control. Once the intervention was assigned, baseline assessment procedures were performed. 


\section{Training Protocol}

Training parameters for both groups consisted of $45 \mathrm{~min}$ Lokomat-based training sessions (not including rest breaks), 3 times/week for 3 mo.

\section{Experimental Intervention: Lokomat-Resisted Body- Weight Supported Treadmill Training (Loko-R)}

BWSTT was implemented using custom software control of the Lokomat [26]. The drives were programmed to apply a velocity-dependent resistance against the hip and knee with the amount of resistance at each joint defined by $M=-B \times v$, where $M$ is the amount of resistance, $B$ is the viscous coefficient (in N-m-s/rad), and $v$ is the joint angular velocity. When $B=0$, no force is applied and the participant can step freely on the treadmill. (Note that in this software control mode, the Lokomat never assists leg movements.) When a value is assigned to $B$, the Lokomat applies a resistance proportional to the instantaneous joint angular velocity.

To determine the resistance level, participants first performed isometric muscle testing using the Lokomat's "L-Force" feature [44]. Participants were secured to the Lokomat and lifted above the treadmill with the BWS harness. For L-Force testing, the Lokomat's legs were fixed, with the hips at $30^{\circ}$ of flexion and the knees at $45^{\circ}$ of flexion, and participants were asked to push as hard as possible against the device. The hip and knee were tested separately, and three trials each were performed to calculate an average maximum voluntary contraction (MVC) for the hip and knee flexors bilaterally. Second, the participant walked with the Lokomat at his or her current treadmill training speed with $B=0$. One to two minutes of data from the Lokomat's hip and knee joint position sensors were recorded at 1,000 Hz. Using a custom-written MATLAB routine (MathWorks; Natick, Massachusetts), the average hip and knee angular velocity during swing were determined. These values were then used to determine the desired $B$ values for training by defining $M$ as 10 percent of MVC of each joint. $B$ values were reassessed in this way every four to six training sessions.

The level of BWS was adjusted to the minimum tolerated by the participant while ensuring appropriate stance phase kinematics $[8,42,45]$. In the first training session, the speed was initiated at $1.0 \mathrm{~km} / \mathrm{h}$ (the lowest speed in the Lokomat). Treadmill speed was subsequently increased by increments of $0.1 \mathrm{~km} / \mathrm{h}$. Tolerance to a given speed was evaluated by observing the participant's ability to place his or her feet anterior to the hip joint at foot contact. If the participant was able to keep up with the treadmill speed for at least $5 \mathrm{~min}$, another increment of $0.1 \mathrm{~km} / \mathrm{h}$ was added. In participants with weak or paralyzed ankle dorsiflexion, the Lokomat's passive foot lifters were used to maintain the ankles in a neutral position and ensure that the foot cleared the treadmill during swing.

Tolerance to training was gauged by using the rating of perceived exertion (RPE) with the Borg CR10 scale [46]. The Borg CR10 was administered at the beginning of each rest break. Participants were also asked to report any pain or symptoms related to autonomic dysreflexia (e.g., excessive sweating, dizziness, nausea, blurred vision) and whether any of these interfered with their ability to continue the training session. Participants took rest breaks as desired.

\section{Control Intervention: Lokomat-Assisted Body Weight- Supported Treadmill Training (Control)}

Participants in this group underwent "conventional" Lokomat-based training, as reported in previous studies, where the Lokomat provides assistance to gait movements [8,41-42]. In this mode, the Lokomat's hip and knee joint motors move the participants' legs along a preset trajectory that is based on normative gait kinematics. Progression of BWS and treadmill speed followed the same protocol as described previously.

\section{Outcome Measures}

To compare training parameters between groups, we calculated a weighted average BWS and treadmill speed (taking into account the amount of time at each BWS/ treadmill speed) for each session. Tolerance to training was estimated by recording the total session duration (giving an indirect measure of the amount of rest required) and RPE. For RPE, values recorded at approximately the midpoint and end of each training session were averaged to obtain a session RPE. We also calculated an "exercise score," modified after Foster et al. [47], to quantify the volume of exercise for comparison between groups. The exercise score was calculated by multiplying session RPE by training duration. Tolerance to training was also gauged by the reports of pain or symptoms related to autonomic dysreflexia.

The primary outcome measure to assess the potential efficacy of Loko-R was skilled walking capacity, as assessed by the Spinal Cord Injury-Functional Ambulation Profile (SCI-FAP) [48]. The SCI-FAP consists of 
seven walking tasks: (1) $5 \mathrm{~m}$ carpet walk, (2) Timed "Up and Go" test, (3) $5 \mathrm{~m}$ obstacle-crossing task, (4) walking up and down a set of four stairs, (5) opening a door and walking through a doorway, (6) stepping up and off a $21 \mathrm{~cm}$ high block, and (7) walking $5 \mathrm{~m}$ while carrying a bag weighing $5 \mathrm{lb}$. The time required to complete each task was multiplied by a factor reflecting the use of assistive aids or personal assistance, and the values for each task were then summed to provide a total score. Lower scores reflect better performance. The SCI-FAP has been shown to be valid and reliable in people with m-iSCI [48]. We also assessed the $10 \mathrm{~m}$ walk test (10MWT), taking an average of three trials at self-selected pace, and $6 \mathrm{~min}$ walk test (6MWT), which are both valid and reliable measures of walking capacity in SCI [49].

\section{Statistical Analysis}

All statistical analyses were assessed at a significance level of 0.05 and conducted using SPSS version 20 (IBM Corporation; Armonk, New York). Descriptive statistics were used to characterize the age, weight, height, time postinjury, and incidence of negative symptoms reported by participants. Student $t$-tests (for parametric measures) or Mann-Whitney $U$-tests (for nonparametric measures) were used to test for differences in outcome measures at baseline between the two groups.

To compare training parameters between groups, BWS and treadmill speed averaged over the first and last three training sessions were compared using a $2 \times 2$ analysis of variance (ANOVA). Inspection of the data showed steady progression of BWS and treadmill speed over the training program across all subjects, so we felt that using the first and last three training sessions would appropriately represent these data. Similarly, to compare tolerance to training between groups, averaged session durations, session RPEs, and exercise scores over the first and last three training sessions were compared using a $2 \times 2$ ANOVA.

For the ambulation outcomes, we conducted a preliminary efficacy analysis involving all participants who did not miss any of the assessment sessions. We also conducted an intention-to-treat analysis in which missing data were imputed by estimation-maximation [50]. Missing data were confirmed to be missing completely at random using Little Chi-square statistic prior to imputation.

We used an analysis of covariance (ANCOVA) to evaluate the potential efficacy of the intervention on the primary dependent variable, SCI-FAP, at posttraining.
Baseline scores were used as the covariate, while group (Loko-R, Control) was the independent factor. Secondary analyses using ANCOVA were also undertaken to determine the effect of the intervention on the SCI-FAP at 1 and 6 mo follow-up, as well as on the 10MWT and $6 \mathrm{MWT}$ at posttraining and 1 and 6 mo follow-up. Data were log-transformed prior to performing the ANCOVA if they were not normally distributed, as determined by the Shapiro-Wilk test of normality. The effect size of group differences was calculated by $\eta^{2}$ to determine the amount of variability in outcome measurements that can be accounted for by the independent variable (group).

\section{RESULTS}

Figure 1 illustrates the enrollment and flow of participants through this pilot randomized controlled trial. Eight individuals were randomized to Loko-R and seven to the Control group. All participants received the treatment to which they were allocated. Two participants who were in the Control group withdrew from the study after the second week of training; one cited difficulties in her personal life and the other contracted pneumonia. One participant in the Loko-R group could not attend the 6 mo follow-up assessment because of his relocation to another city. Baseline demographics and characteristics of study participants are summarized in Table 1. There were no significant between-group differences in any of the demographic or outcome measures.

\section{Training Parameters}

There was no significant between-group difference in BWS $(F(1,11)=4.3, p=0.06)$. BWS significantly decreased from the first to last week of training $(F(1,11)=$ $17.0, p=0.002)$. In the Control group, BWS decreased from $25.2 \pm 14.0$ percent in the first week to $12.9 \pm$ 6.8 percent in the last week of training. In the Loko-R group, BWS decreased from $37.9 \pm 11.9$ percent in the first week to $19.1 \pm 7.7$ percent in the last week of training.

Treadmill speed was significantly lower in the Loko$\mathrm{R}$ group $(F(1,11)=23.1, p=0.001)$ and significantly increased from the first to the last week of training $(F(1,11)=41.6, p<0.001)$. In the Control group, average treadmill speed increased from $1.6 \pm 0.2 \mathrm{~km} / \mathrm{h}$ in the first week to $1.9 \pm 0.3 \mathrm{~km} / \mathrm{h}$ in the last week of training. In the Loko-R group, average treadmill speed increased from 


\section{Enrollment}

Assessed for eligibility $(n=17)$

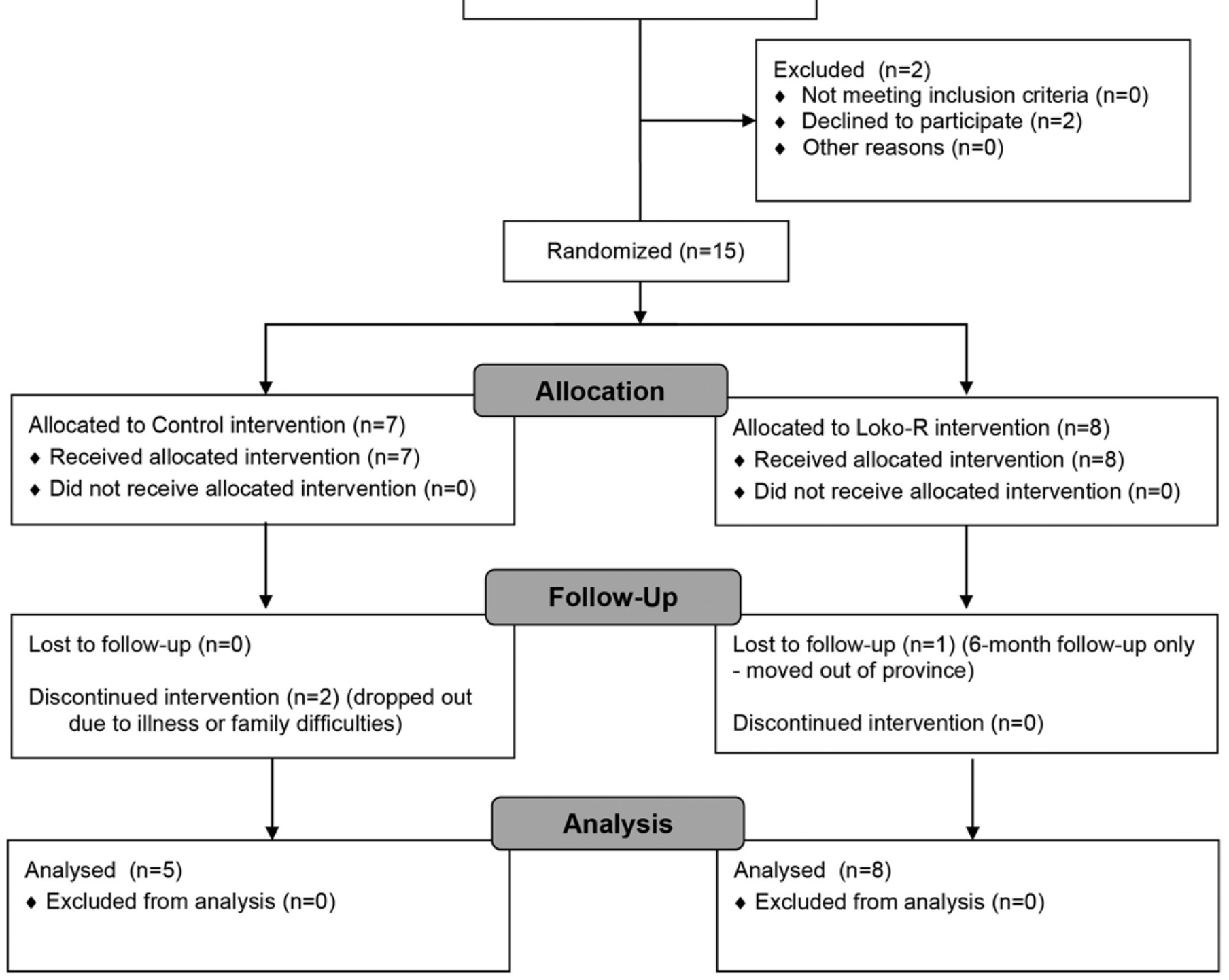

Figure 1.

Flow of participants through study. Loko-R = Lokomat-applied resistance.

$1.2 \pm 0.1 \mathrm{~km} / \mathrm{h}$ in the first week to $1.7 \pm 0.2 \mathrm{~km} / \mathrm{h}$ in the last week of training.

\section{Tolerance to Training}

Among the participants in the Control group, there were 6 reports of fatigue, 2 reports of light-headedness, and 23 reports of pain/soreness (primarily low back) over the course of the training program. Among the subjects in Loko-R, there were 3 reports of excessive sweating, 1 report of excessive headache, 15 reports of fatigue, 2 reports of light-headedness, 1 report of blurred vision, and 38 reports of pain/soreness (primarily low back and 
Table 1.

Subject characteristics.

\begin{tabular}{|c|c|c|c|c|c|c|c|c|c|}
\hline \multirow[b]{2}{*}{ Subject } & \multirow[b]{2}{*}{ Sex } & \multirow[b]{2}{*}{ Age (yr) } & \multirow[b]{2}{*}{ AIS } & \multirow{2}{*}{$\begin{array}{l}\text { Injury } \\
\text { Level }\end{array}$} & \multirow[b]{2}{*}{ Etiology } & \multirow[b]{2}{*}{ Chronicity (yr) } & \multicolumn{3}{|c|}{ Baseline Scores } \\
\hline & & & & & & & SCI-FAP & $\begin{array}{c}\text { 10MWT } \\
(\mathrm{m} / \mathrm{s})\end{array}$ & $\begin{array}{c}\text { 6MWT } \\
\text { (m) }\end{array}$ \\
\hline \multicolumn{10}{|l|}{ Control } \\
\hline $\mathrm{S} 2$ & M & 63 & AIS D & $\mathrm{C} 5$ & Trauma & 2 & 58 & 0.33 & 164 \\
\hline $\mathrm{S} 3$ & M & 59 & AIS D & $\mathrm{C} 4$ & Trauma & 5 & 1,605 & 0.05 & 23 \\
\hline S6 & $\mathrm{F}$ & 52 & AIS C & $\mathrm{C} 4 / 5$ & Trauma & 2 & 1,800 & 0.03 & 9 \\
\hline S7 & $\mathrm{F}$ & 55 & AIS C & $\mathrm{T} 7$ & Trauma & 20 & 587 & 0.12 & 43 \\
\hline \multicolumn{10}{|c|}{ Experimental (Loko-R) } \\
\hline S8 & $\mathrm{F}$ & 53 & AIS D & T3 & Hemorrhage & 2 & 83 & 0.34 & 139 \\
\hline S9 & M & 28 & AIS C & C6 & Trauma & 2 & 1,607 & 0.15 & 26 \\
\hline S13 & M & 28 & AIS C & $\mathrm{C} 5 / 6$ & Trauma & 7 & 946 & 0.06 & 23 \\
\hline S14 & M & 60 & AIS D & $\mathrm{T} 10$ & Viral & 4 & 1,087 & 0.12 & 36 \\
\hline $\mathrm{S} 15$ & M & 31 & AIS D & $\mathrm{T} 4$ & Trauma & 6 & 601 & 0.09 & 22 \\
\hline
\end{tabular}

legs). All subjects in both groups reported experiencing one of these symptoms at least once during the $3 \mathrm{mo}$ training program, and there was an average of six reports of pain/soreness per subject in both groups. There were 19 instances across four participants ( 1 from the Control group and 3 from Loko-R) where headache, fatigue, or pain/soreness in the low back or leg interrupted training. However, all participants included in the final analysis completed 36 training sessions, except for one in Loko-R who ended at session 33 (due to scheduling conflict).

The average total session duration (including rest breaks) was not different between groups $(F(1,11)=0.11$, $p=0.75)$ nor from the first to the last week of training $(F(1,11)=2.5, p=0.14)$. In the Control group, average total session duration in the first week was $66 \pm 16 \mathrm{~min}$ and in the last week was $59 \pm 12 \mathrm{~min}$. In the Loko-R group, the average total session duration in the first week was $71 \pm 12 \mathrm{~min}$ and in the last week was $76 \pm 13 \mathrm{~min}$.

Session RPE was significantly different between the groups $(F(1,11)=8.7, p=0.01)$ but not between the first and last week of training $(F(1,11)=0.06, p=0.81)$. Average session RPE in the Control group in the first week was $2.5 \pm 1.2$ and in the last week was $2.6 \pm 0.5$. In the Loko-R group, average session RPE in the first week was $4.0 \pm 1.6$ and in the last week was $4.1 \pm 1.2$.
The overall exercise score was also significantly different between the two groups $(F(1,11)=5.6, p=0.04)$, but not between the first and last week of training $(F(1,11)=3.1, p=0.10)$. The average exercise score in the Control group in the first week was $94.5 \pm 41.5$ and in the last week was $116.2 \pm 30.2$. In the Loko-R group, the average exercise score in the first week was $163.3 \pm 71.2$ and in the last week was $191.1 \pm 64.9$.

\section{Skilled Walking}

Results for the SCI-FAP at posttraining are shown in Table 2, and raw data are shown in Figure 2(a). The Loko-R group showed a significantly greater improvement in the SCI-FAP at posttraining than the Control. Compared with baseline, posttraining SCI-FAP scores decreased by 204 points (standard deviation [SD]: 207, 95\% confidence interval [CI]: -348 to -61$)$ in the Loko$\mathrm{R}$ group but only by 18 points (SD: $36,95 \% \mathrm{CI}:-50$ to 14) in the Control group.

Improvements in the SCI-FAP were retained at 1 and 6 mo follow-up (Table 2). In the Loko-R group, SCI-FAP scores at 1 and 6 mo follow-up were 217 (SD: 213, 95\% CI: -364 to -69 ) and 220 (SD: $249,95 \%$ CI: -404 to -36 ) points less than baseline, respectively. In the Control group, the SCI-FAP scores at 1 and 6 mo follow-up were 
JRRD, Volume 52, Number 1, 2015

Table 2.

Efficacy and intent-to-treat analysis of Spinal Cord Injury-Functional Ambulation Profile (SCI-FAP) scores.

\begin{tabular}{|c|c|c|c|c|c|}
\hline \multirow{2}{*}{ Analysis } & \multirow{2}{*}{ Mean \pm SD } & \multicolumn{4}{|c|}{ ANCOVA } \\
\hline & & Adjusted Mean & $F$ & $p$-Value & $\eta^{2}$ \\
\hline \multicolumn{6}{|l|}{ Efficacy Analysis } \\
\hline Control $(n=7)$ & $669 \pm 738$ & - & & & \\
\hline Loko-R $(n=8)$ & $602 \pm 570$ & - & & & \\
\hline Posttraining $^{*}$ & & & $F_{1,10}=19.6$ & 0.001 & 0.66 \\
\hline 1 mo Follow-Up ${ }^{*}$ & & & $F_{1,10}=8.6$ & 0.02 & 0.46 \\
\hline Control $(\mathrm{n}=5)$ & $694 \pm 859$ & 629 & & & \\
\hline Loko-R $(n=8)$ & $385 \pm 367$ & 425 & & & \\
\hline 6 mo Follow-Up & & & $F_{1.9}=5.4$ & 0.046 & 0.37 \\
\hline Control $(n=5)$ & $679 \pm 827$ & 620 & & & \\
\hline Control $(n=7)$ & $652 \pm 714$ & 623 & & & \\
\hline Loko-R $(n=8)$ & $397 \pm 365$ & 423 & & & \\
\hline 1 mo Follow-Up ${ }^{*}$ & & & $F_{1,12}=14.3$ & 0.003 & 0.54 \\
\hline Control $(n=7)$ & $635 \pm 710$ & 606 & & & \\
\hline Loko-R $(n=8)$ & $385 \pm 367$ & 411 & & & \\
\hline 6 mo Follow-Up ${ }^{*}$ & & & $F_{1,12}=10.3$ & 0.008 & 0.46 \\
\hline Control $(n=7)$ & $624 \pm 683$ & 595 & & & \\
\hline Loko-R $(n=8)$ & $382 \pm 364$ & 406 & & & \\
\hline
\end{tabular}

Note: ANCOVA results are between-subjects comparison of SCI-FAP between Control and Loko-R at each of outcome assessment time points. For efficacy analysis, analyses were performed with case-wise deletion of missing data (13\% for posttraining and 1 mo follow-up comparisons, 20\% for 6-month follow-up comparisons). For intent-to-treat, missing data were imputed by expectation-maximation method. Adjusted mean values were obtained from ANCOVA output and estimate mean values after controlling for covariates.

*Statistically significant differences.

ANCOVA $=$ analysis of covariance, Loko- $\mathrm{R}=$ Locomat-applied resistance, $\mathrm{SD}=$ standard deviation .

36 (SD: $70,95 \%$ CI: -97 to 25 ) and 50 (SD: $131,95 \%$ CI: -165 to 65$)$ points less than baseline, respectively. There was a significant effect of group at all assessment time points with respect to baseline. Intent-to-treat analysis revealed the same pattern (Table 2).

Figure 3 illustrates the change in SCI-FAP scores at posttraining compared with baseline plotted against initial 10MWT speed. Five of the eight participants in the Loko-R group showed changes in SCI-FAP scores that exceeded the 95 percent minimal detectable change (MDC95) of 92 points [51]. No one with an initial walking speed $>0.35 \mathrm{~m} / \mathrm{s}$ nor anyone from the Control group showed changes in SCI-FAP scores beyond the MDC95.

\section{Overground Walking Speed and Distance}

Raw data from the 10MWT and 6MWT at pre- and posttraining are shown in Figures 2(b) and (c). There was an increase in the 10MWT and 6MWT across time, but there was no significant difference in these outcomes between groups (Tables 3 and 4). Across all subjects in both groups, the 10MWT increased by $0.10 \mathrm{~m} / \mathrm{s}$ (SD: $0.10,95 \%$ CI: 0.05 to 0.16 ) compared with baseline. Walking speed at 1 mo and 6 mo follow-up assessments increased by $0.12 \mathrm{~m} / \mathrm{s}$ (SD: $0.12,95 \% \mathrm{CI}: 0.05$ to 0.18 ) and 0.09 (SD: $0.11,95 \%$ CI: 0.03 to 0.15 ), respectively (Table 3). For the 6MWT, posttraining walking distance increased by $19.6 \mathrm{~m}$ (SD: $18.9,95 \% \mathrm{CI}: 9.3$ to 29.9 ) compared with baseline. Walking distance at 1 mo and 6 mo follow-up assessments increased by $42.5 \mathrm{~m}$ (SD: 62.1, 95\% CI: 8.8 to 76.2 ) and $56.9 \mathrm{~m}$ (SD: $54.5,95 \% \mathrm{CI}$ : 26.1 to 87.7 ), respectively (Table 4). Intent-to-treat analysis revealed the same pattern in 10MWT and 6MWT outcomes at all time points between groups (Tables $\mathbf{3}$ and $\mathbf{4}$ ). 
(a)

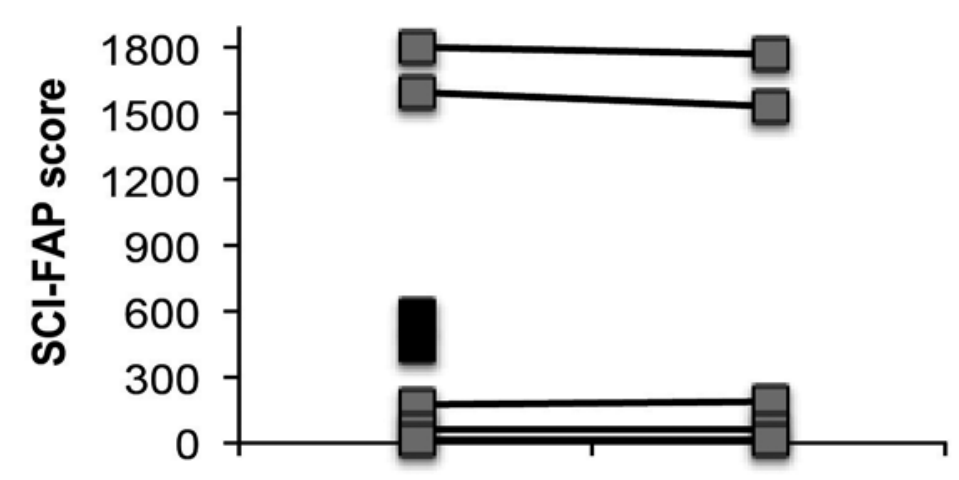

(b)

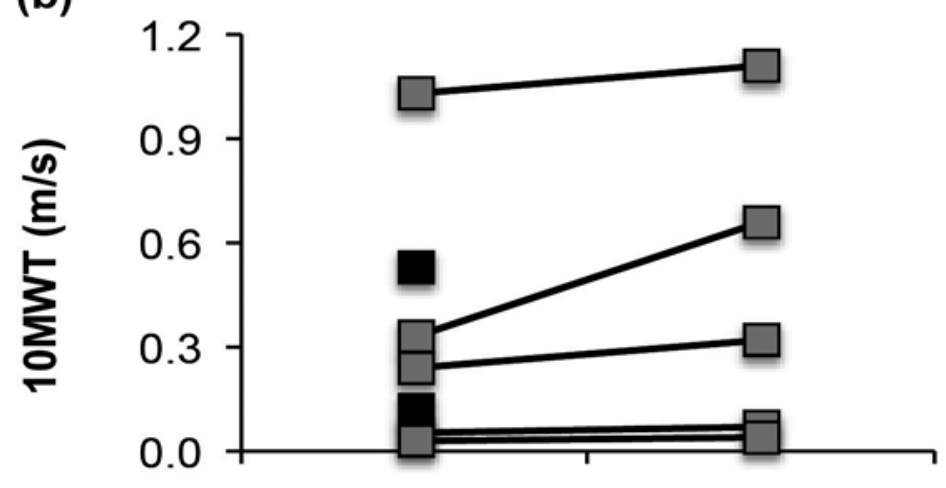

(c)

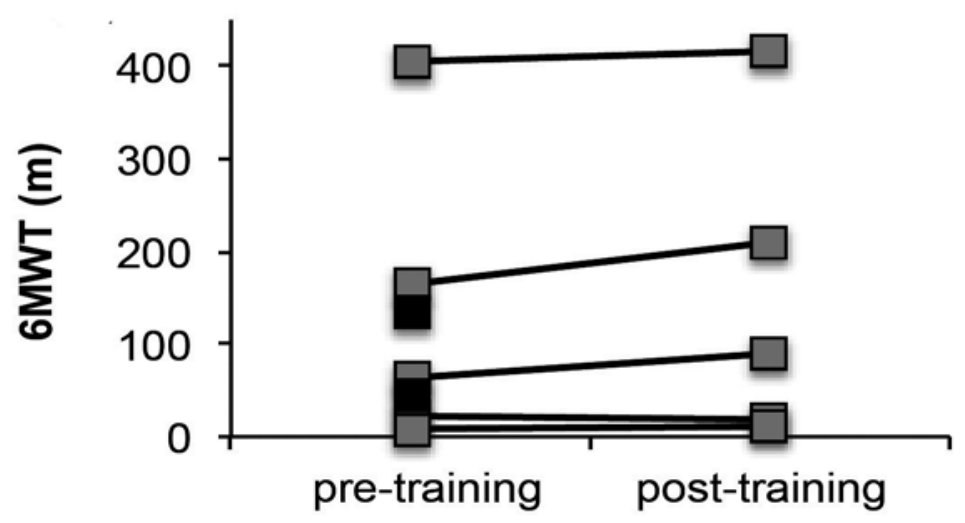

\section{Loko-R group}
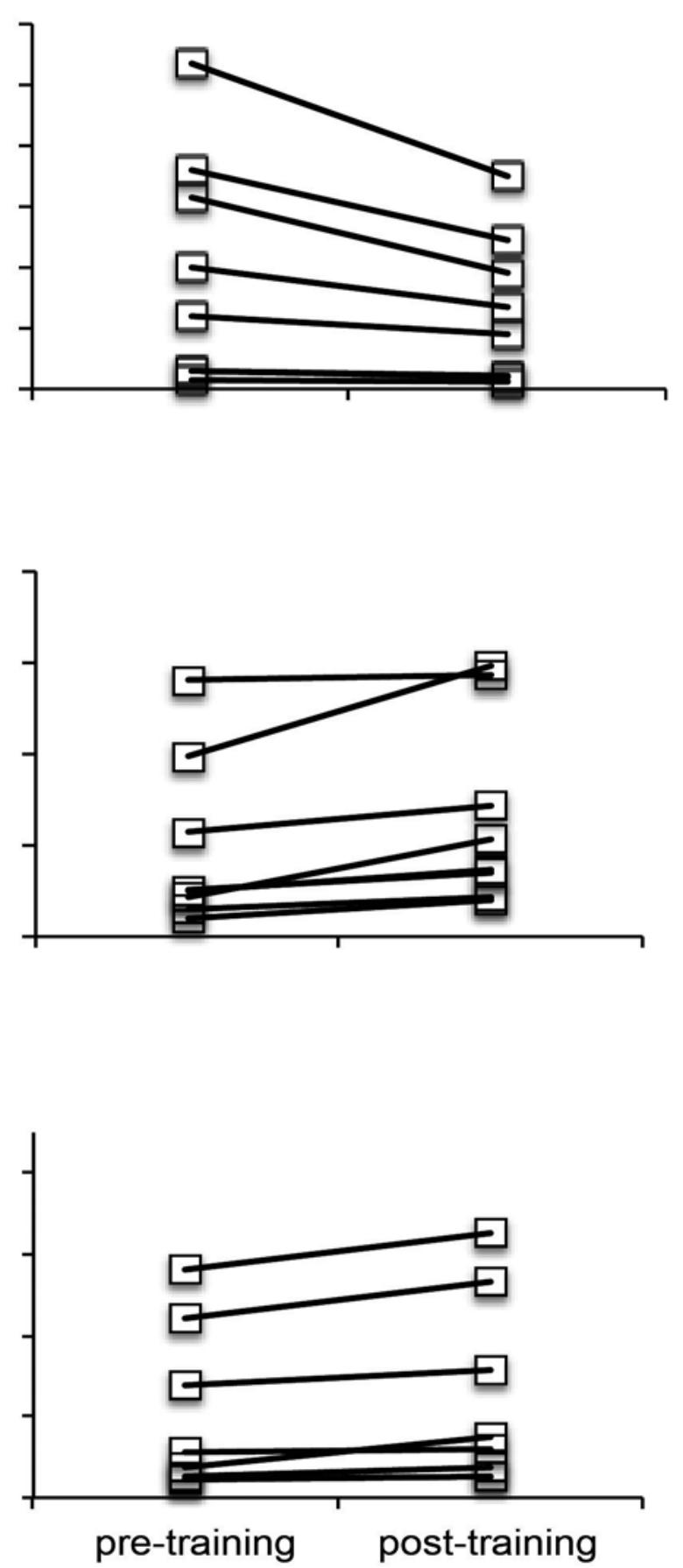

Figure 2.

Raw data of (a) Spinal Cord Injury-Functional Ambulation Profile (SCI-FAP), (b) 10 m walk test (10MWT), and (c) 6 min walk test (6MWT) at pre- and posttraining from all participants. Data from participants in Control group are plotted in left column and those from Lokomat-applied resistance (Loko-R) group are plotted in right column on same vertical axis scale. Black symbols in Control group plots represent pretraining data from two participants who dropped out after second week of training. 


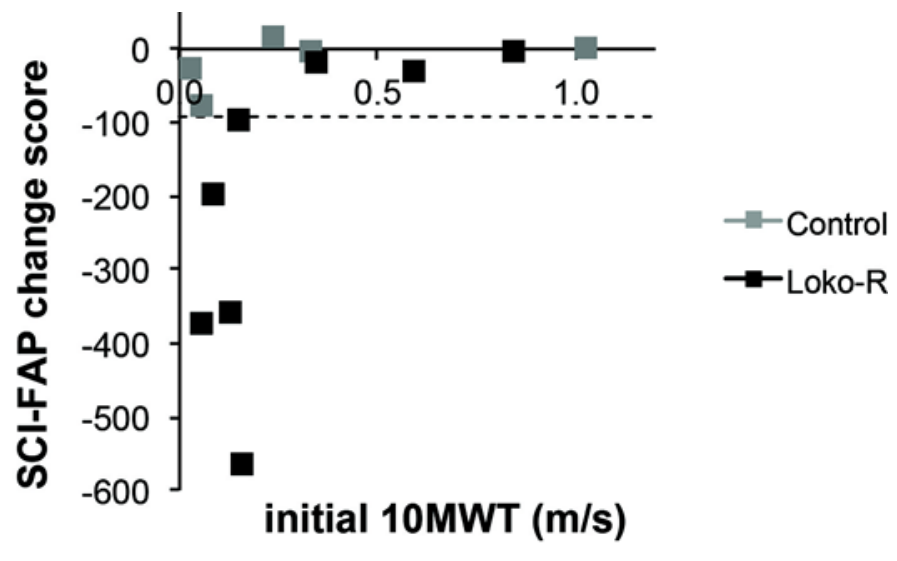

Figure 3.

Change in skilled walking function following Lokomat-applied resistance (Loko-R) training. Change in Spinal Cord InjuryFunctional Ambulation Profile (SCI-FAP) scores at posttraining is plotted against initial walking capacity (10 m walk test [10MWT]) for each participant. Dotted horizontal line denotes 95\% minimal detectable change of SCI-FAP.

\section{DISCUSSION}

In this pilot study, we showed that Loko-R could feasibly be combined with BWSTT in people with chronic $\mathrm{m}$-iSCI. Loko-R is more intensive than standard Lokomat training, and there were more reports of pain/soreness among the participants in the Loko-R group. Nevertheless, there were no dropouts during Loko-R training and all participants could complete the prescribed number of training sessions. Our results also suggest that Loko-R may be beneficial for enhancing skilled walking function in people with chronic m-iSCI. For the relatively simpler tests of overground walking speed and distance, we observed significant improvements with training, but there were no differences between groups. Further studies are warranted to help us understand how best to integrate Loko-R training along the continuum of gait training strategies and whether a lower intensity of Loko$\mathrm{R}$ training (e.g., less resistance) can enable similar functional benefits while reducing the incidence of pain/soreness experienced by participants.

\section{Methodological Considerations}

This was a small pilot study and, after accounting for drop-outs, included five subjects in the Control group and eight in Loko-R (with another drop-out at 6 mo). However, the reasons for dropping out were unrelated to the training, and there were no drop-outs from the Loko-R group during the training period, supporting the feasibility of this approach. Despite the small sample size, we could still detect a statistically significant difference in SCI-FAP scores between groups and across time. However, further trials with larger sample sizes are certainly warranted to confirm the effect of Loko-R on skilled walking function.

There were some differences between the groups in terms of their training parameters and tolerance. There were more reports of fatigue and pain/soreness from participants in the Loko-R group. The exercise scores as well as session RPE were higher in the Loko-R group than in the Control, suggesting that they experienced a higher training intensity. Higher training intensity would presumably affect overall gait function, including endurance. While we did observe differences in SCI-FAP scores, there were no differences in the 10MWT or 6MWT between the groups. If the differences in intensity had an effect, one would expect that the Loko-R group would have shown better outcomes in all of the walking measures, not just the SCI-FAP.

\section{Motor Learning in Gait Rehabilitation}

The ability to generalize is considered a hallmark of learning, as opposed to rote memorization [52]. An interesting result from this pilot study was that it may be possible to improve skilled, overground walking with a treadmill-based intervention. Previous studies in chronic SCI indicated the superiority of overground to treadmillbased training paradigms on walking speed [16] or the equivalence of overground versus treadmill-based training in subacute SCI [10]. One of the hypothesized benefits of overground gait training is that it challenges dynamic balance control during functional gait tasks [53]. Overground task-specific training programs providing explicit practice of different walking skills have been introduced for people with SCI [53] as well as stroke [54]. Musselman et al. compared BWSTT with an overground training program involving practice of a variety of walking tasks, including negotiating obstacles, stairs, steps, and sloped surfaces [53]. While improvements in walking outcomes were observed after both types of training, subjects tended to show greater improvements in skilled walking following the overground training program.

The possibility of improvements in overground skilled walking with treadmill-based Loko-R training could be indicative of task- and context-related generalization 
Table 3.

Efficacy and intent-to-treat analysis of $10 \mathrm{~m}$ walk test (10MWT).

\begin{tabular}{|c|c|c|c|c|c|}
\hline \multirow{2}{*}{ Analysis } & \multirow{2}{*}{ Mean \pm SD } & \multicolumn{4}{|c|}{ ANCOVA } \\
\hline & & Adjusted Mean & $F$ & $p$-Value & $\eta^{2}$ \\
\hline \multicolumn{6}{|l|}{ Efficacy Analysis } \\
\hline \multicolumn{3}{|l|}{ Baseline } & \multirow[t]{3}{*}{-} & \multirow[t]{3}{*}{-} & \multirow[t]{3}{*}{-} \\
\hline Control $(n=7)$ & $0.33 \pm 0.35$ & - & & & \\
\hline Loko-R $(n=8)$ & $0.29 \pm 0.28$ & - & & & \\
\hline \multicolumn{3}{|l|}{ Posttraining } & $F_{1,10}=0.57$ & 0.47 & 0.05 \\
\hline \multicolumn{3}{|l|}{1 mo Follow-up } & \multirow[t]{3}{*}{$F_{1,10}=0.04$} & \multirow[t]{3}{*}{0.85} & \multirow[t]{3}{*}{0.004} \\
\hline Control $(n=5)$ & $0.48 \pm 0.47$ & 0.45 & & & \\
\hline Loko-R $(n=8)$ & $0.39 \pm 0.29$ & 0.41 & & & \\
\hline \multicolumn{3}{|l|}{6 mo Follow-Up } & \multirow[t]{2}{*}{$F_{1,9}=0.005$} & \multirow[t]{2}{*}{0.95} & \multirow[t]{2}{*}{0.001} \\
\hline Control $(n=5)$ & $0.45 \pm 0.45$ & 0.44 & & & \\
\hline Control $(n=5)$ & $0.44 \pm 0.39$ & 0.41 & \multirow{2}{*}{$F_{1,12}=0.48$} & \multirow{2}{*}{0.50} & \multirow{2}{*}{0.04} \\
\hline Loko-R $(n=7)$ & $0.40 \pm 0.31$ & 0.42 & & & \\
\hline \multicolumn{3}{|l|}{1 mo Follow-Up } & \multirow[t]{3}{*}{$F_{1,12}=0.004$} & \multirow[t]{3}{*}{0.95} & \multirow[t]{3}{*}{0.00} \\
\hline Control $(n=5)$ & $0.47 \pm 0.40$ & 0.45 & & & \\
\hline Loko-R $(n=7)$ & $0.39 \pm 0.29$ & 0.41 & & & \\
\hline \multicolumn{2}{|l|}{6 mo Follow-Up } & & \multirow[t]{3}{*}{$F 1,12=0.004$} & \multirow[t]{3}{*}{0.95} & \multirow[t]{3}{*}{0.00} \\
\hline Control $(n=5)$ & $0.44 \pm 0.39$ & 0.42 & & & \\
\hline Loko-R $(n=7)$ & $0.37 \pm 0.29$ & 0.39 & & & \\
\hline $\begin{array}{l}\text { Note: ANCOVA results are betwe } \\
\text { sis, analyses were performed with } \\
\text { sons). For intent-to-treat, missing } \\
\text { mean values after controlling for } \\
\text { ANCOVA = analysis of covarianc }\end{array}$ & $\begin{array}{l}\text { of } 10 \mathrm{MWT} \text { bet } \\
\text { f missing data }(1 \\
\text { expectation-maxi } \\
\text {-applied resistanc }\end{array}$ & $\begin{array}{l}\text { een Control and Loko- } \\
0 \text { for posttraining and } \\
\text { ation method. Adjustec } \\
\mathrm{SD}=\text { standard deviati }\end{array}$ & $\begin{array}{l}\mathrm{R} \text { at each of outcome } \\
\text { mo follow-up com } \\
\text { mean values were o } \\
\text { n. }\end{array}$ & $\begin{array}{l}\text { ssment time } \\
\text { ons, } 20 \% \text { for } \\
\text { led from } \mathrm{ANC}\end{array}$ & $\begin{array}{l}\text { officacy } \\
\text { ow-up cc } \\
\text { put and e }\end{array}$ \\
\hline
\end{tabular}

of locomotor gains. Task-related generalization is indicated by the improvements in walking capacity generalized to skills (e.g., obstacle crossing) that were not specifically trained. Context-related generalization is suggested by the fact that improvements transferred from the treadmill to an overground situation. In considering the role of robotics in rehabilitation, Huang and Krakauer raised the important issue of whether training with robotic devices only facilitates learning of the use of a new tool (i.e., the robot) as opposed to (re)learning control of the limbs [55]. Our results are consistent with the notion that robot-resisted treadmill training engages feedback-error processes to facilitate relearning. Loko-R training, and indeed other robot-based flexible-trajectory training paradigms $[32,56]$, provides several training characteristics that would facilitate motor learning in this manner. These include (1) enhanced sensory input, (2) greater variability during training, and (3) more active participation in the production of locomotor activity.

\section{Sensory Feedback Enhances Flexor Muscle Activity}

Many skilled walking tasks require the ability to precisely control foot trajectory height during swing and advance the foot to an appropriate landing position. During swing, foot clearance height is especially sensitive to changes in knee flexion [57], and the higher stepping required for obstacle crossing is primarily because of a knee flexor strategy [58-60]. Adaptations to Lokomatapplied velocity-dependent resistance include strategies that enhance swing phase initiation and foot clearance height, such as increased hamstrings and rectus femoris activity [26]. Moreover, we and others have shown that when the resistance is removed aftereffects are elicited, suggesting feedforward adaptation to the new dynamic 
JRRD, Volume 52, Number 1, 2015

Table 4.

Efficacy and intent-to-treat analysis of 6 min walk test (6MWT).

\begin{tabular}{|c|c|c|c|c|c|}
\hline \multirow{2}{*}{ Analysis } & \multirow{2}{*}{ Mean \pm SD } & \multicolumn{4}{|c|}{ ANCOVA } \\
\hline & & Adjusted Mean & $F$ & $p$-Value & $\eta^{2}$ \\
\hline \multicolumn{6}{|l|}{ Efficacy Analysis } \\
\hline \multicolumn{3}{|l|}{ Baseline } & \multirow[t]{3}{*}{-} & \multirow[t]{3}{*}{-} & \multirow[t]{3}{*}{ - } \\
\hline Control $(n=7)$ & $120 \pm 138$ & - & & & \\
\hline Loko-R $(n=8)$ & $100 \pm 102$ & - & & & \\
\hline \multicolumn{3}{|l|}{ Posttraining } & $F_{1,10}=1.18$ & 0.30 & 0.11 \\
\hline \multicolumn{3}{|l|}{1 mo Follow-Up } & \multirow{3}{*}{$F_{1,10}=0.002$} & \multirow[t]{3}{*}{0.96} & \multirow[t]{3}{*}{0.00} \\
\hline Control $(n=5)$ & $197 \pm 177$ & 179 & & & \\
\hline Loko-R $(n=8)$ & $129 \pm 90$ & 140 & & & \\
\hline \multicolumn{3}{|l|}{6 mo Follow-Up } & \multirow[t]{2}{*}{$F_{1,9}=0.44$} & \multirow[t]{2}{*}{0.52} & \multirow[t]{2}{*}{0.05} \\
\hline Control $(n=5)$ & $191 \pm 172$ & 179 & & & \\
\hline Control $(n=5)$ & $139 \pm 143$ & 125 & \multirow{2}{*}{$F_{1,12}=1.11$} & \multirow{2}{*}{0.31} & \multirow{2}{*}{0.08} \\
\hline Loko-R $(n=8)$ & $122 \pm 117$ & 132 & & & \\
\hline \multicolumn{3}{|l|}{1 mo Follow-Up } & \multirow[t]{3}{*}{$F_{1,12}=0.08$} & \multirow[t]{3}{*}{0.78} & \multirow[t]{3}{*}{0.01} \\
\hline Control $(n=5)$ & $185 \pm 148$ & 176 & & & \\
\hline Loko-R $(n=8)$ & $129 \pm 90$ & 138 & & & \\
\hline \multicolumn{2}{|l|}{6 mo Follow-Up } & & \multirow[t]{3}{*}{$F_{1,12}=0.55$} & \multirow[t]{3}{*}{0.47} & 0.04 \\
\hline Control $(n=5)$ & $179 \pm 144$ & 169 & & & \\
\hline Loko-R $(n=8)$ & $155 \pm 118$ & 164 & & & \\
\hline $\begin{array}{l}\text { Note: ANCOVA results are betwe } \\
\text { analyses were performed with ca } \\
\text { For intent-to-treat, missing data } \\
\text { values after controlling for covari } \\
\text { ANCOVA = analysis of covarian }\end{array}$ & $\begin{array}{l}\text { of } 6 \mathrm{MWT} \text { betw } \\
\text { sing data }(13 \% \mathrm{f} \\
\text { ation-maximatio } \\
\text { applied resistanc }\end{array}$ & $\begin{array}{l}\text { Control and Loko-R } \\
\text { posttraining and } 1 \mathrm{mo} \\
\text { method. Adjusted mear } \\
\mathrm{SD}=\text { standard deviati }\end{array}$ & $\begin{array}{l}\text { t each of outcome } \\
\text { follow-up compari } \\
\text { values were obtain }\end{array}$ & $\begin{array}{l}\text { ment time pc } \\
20 \% \text { for } 6 \mathrm{~m} \\
\mathrm{~m} \text { ANCOVA }\end{array}$ & $\begin{array}{l}\text { ficacy a } \\
\text { compa } \\
\text { estima }\end{array}$ \\
\hline
\end{tabular}

environment [24-31]. Aftereffects persist even when subjects subsequently step overground [32]. Thus, given that adaptive strategies to Loko- $\mathrm{R}$ include responses that facilitate the initiation of swing and enhance foot clearance height [26,31], repeated exposure to Loko-R over the course of training could have resulted in enhanced dynamic control of the lower limb, facilitating the functional improvements in skilled walking.

\section{Movement Variability During Training}

There is increasing evidence that providing more variable practice conditions during training enhances motor performance [56,61-63]. This is also implied from clinical research showing that overground gait training or therapist-assisted BWSTT enables better ambulatory outcomes in people with SCI or stroke than with robotguided training [16,61]. The rigid imposition of movement trajectories by robot-assisted training limits the variability with which the lower limbs are moved and consequently could interfere with the nervous system's ability to effectively relearn gait patterns [61-62]. Indeed, variability during practice is seen as a key feature for facilitating learning because the nervous system is presented with repeated (and varied) opportunities to experience errors and solve motor problems [55], as opposed to simply learning how to reproduce an imposed trajectory [63]. Others have also suggested that variability or "noise" during training provides a stochastic resonance to help reinforce convergent synaptic connections from central and sensory inputs to the locomotor circuitry [62].

\section{Active Engagement in Training}

Lokomat-applied resistance would also have required greater engagement during training to avoid toe drag and stumbling. In contrast, subjects in the Control group would not be as compelled to be actively involved in 
their training. Our results are consistent with and extend those of Yen et al., who found that after a single bout of robot-resisted treadmill walking, subjects showed aftereffects (longer stride length) when subsequently asked to step overground [32]. They also speculated that the transfer of locomotor aftereffects from resisted treadmill walking to overground stepping could have been related to the level of active engagement.

Greater cognitive engagement during training could have elicited greater involvement of cortical regions associated with gait, which are particularly involved in the adjustments of motor output during swing [64-66]. Indeed, it has been shown that corticospinal excitability is tuned according to the level of cognitive engagement during gait [67-68]. In addition, the improvement in locomotor control in people with m-iSCI is associated with increased corticospinal drive to leg muscles [6970]. Thus, given the role of the primary motor cortex in the control of skilled locomotion [64-66], as well as evidence that corticospinal excitability is modulated with locomotor adaptations [71-73] and associated with locomotor recovery following SCI [69-70,74-75], it is possible that the improvements in skilled walking following Loko-R training was associated with enhanced cortical excitability secondary to greater active engagement during training.

\section{CONCLUSIONS}

There has been some controversy surrounding the effectiveness of BWSTT over "conventional" rehabilitation; however, the results of this pilot study suggest new promise for the value of robotics-based BWSTT incorporating principles of motor learning. Training with Loko-R can be feasibly implemented in people with chronic miSCI. This study also highlights the importance of including outcome measures that assess walking skills that represent the requirements of everyday mobility. To our knowledge, this study is the first to suggest that improvements in skilled walking following a treadmill-based gait rehabilitation program may be possible. Given the promising results of this pilot study, a larger randomized controlled trial with more subjects is warranted to confirm the effects of locomotor training with Loko-R.

\section{ACKNOWLEDGMENTS}

\section{Author Contributions:}

Study concept and design: T. Lam, A. Krassioukov, J. J. Eng.

Acquisition of data: K. Pauhl, A. Ferguson, A. Krassioukov.

Analysis and interpretation of data: T. Lam, K. Pauhl, A. Ferguson,

R. N. Malik.

Drafting of manuscript: T. Lam, R. N. Malik.

Statistical analysis: T. Lam, J. J. Eng.

Financial Disclosures: The authors have declared that no competing interests exist.

Funding/Support: This material was based on work supported by the British Columbia Medical Services Foundation and the Canadian Institutes of Health Research. T. Lam is supported by a Canadian Institute of Health Research New Investigator Award.

Additional Contributions: We thank all our research participants and the numerous volunteers for their generous time commitment to this study.

Institutional Review: All participants provided written informed consent and all procedures were approved by the University of British Columbia Clinical Research Ethics Board.

Participant Follow-Up: The authors plan to inform participants of study publication.

\section{REFERENCES}

1. Marino RJ, Ditunno JF Jr, Donovan WH, Maynard F Jr. Neurologic recovery after traumatic spinal cord injury: Data from the Model Spinal Cord Injury Systems. Arch Phys Med Rehabil. 1999;80(11):1391-96.

[PMID:10569432] http://dx.doi.org/10.1016/S0003-9993(99)90249-6

2. Burns SP, Golding DG, Rolle WA Jr, Graziani V, Ditunno JF Jr. Recovery of ambulation in motor-incomplete tetraplegia. Arch Phys Med Rehabil. 1997;78(11):1169-72. [PMID:9365343] http://dx.doi.org/10.1016/S0003-9993(97)90326-9

3. Barbeau H, Fung J. The role of rehabilitation in the recovery of walking in the neurological population. Curr Opin Neurol. 2001;14(6):735-40. [PMID:11723381] http://dx.doi.org/10.1097/00019052-200112000-00009

4. Wessels M, Lucas C, Eriks I, de Groot S. Body weight-supported gait training for restoration of walking in people with an incomplete spinal cord injury: A systematic review. J Rehabil Med. 2010;42(6):513-19. [PMID:20549154] http://dx.doi.org/10.2340/16501977-0525

5. Colombo G, Wirz M, Dietz V. Driven gait orthosis for improvement of locomotor training in paraplegic patients. Spinal Cord. 2001;39(5):252-55. [PMID:11438840] http://dx.doi.org/10.1038/sj.sc.3101154

6. Behrman AL, Harkema SJ. Locomotor training after human spinal cord injury: A series of case studies. Phys Ther. 2000;80(7):688-700. [PMID:10869131] 
7. Barbeau H, Blunt R. A novel approach using body weight support to retrain gait in spastic paretic subjects. In: Wernig A, editor. Plasticity of motoneuronal connections. New York (NY): Elsevier Science; 1991. p. 461-74.

8. Wirz M, Zemon DH, Rupp R, Scheel A, Colombo G, Dietz V, Hornby TG. Effectiveness of automated locomotor training in patients with chronic incomplete spinal cord injury: A multicenter trial. Arch Phys Med Rehabil. 2005;86(4): 672-80. [PMID:15827916] http://dx.doi.org/10.1016/j.apmr.2004.08.004

9. Edgerton VR, Leon RD, Harkema SJ, Hodgson JA, London N, Reinkensmeyer DJ, Roy RR, Talmadge RJ, Tillakaratne NJ, Timoszyk W, Tobin A. Retraining the injured spinal cord. J Physiol. 2001;533(Pt 1):15-22.

[PMID:11351008] http://dx.doi.org/10.1111/j.1469-7793.2001.0015b.x

10. Dobkin B, Apple D, Barbeau H, Basso M, Behrman A, Deforge D, Ditunno J, Dudley G, Elashoff R, Fugate L, Harkema S, Saulino M, Scott M; Spinal Cord Injury Locomotor Trial Group. Weight-supported treadmill vs overground training for walking after acute incomplete SCI. Neurology. 2006;66(4):484-93. [PMID:16505299] http://dx.doi.org/10.1212/01.wnl.0000202600.72018.39

11. Dobkin B, Barbeau H, Deforge D, Ditunno J, Elashoff R, Apple D, Basso M, Behrman A, Harkema S, Saulino M, Scott M; Spinal Cord Injury Locomotor Trial Group. The evolution of walking-related outcomes over the first 12 weeks of rehabilitation for incomplete traumatic spinal cord injury: The multicenter randomized Spinal Cord Injury Locomotor Trial. Neurorehabil Neural Repair. 2007; 21(1):25-35. [PMID:17172551] http://dx.doi.org/10.1177/1545968306295556

12. Dietz V. Good clinical practice in neurorehabilitation. Lancet Neurol. 2006;5(5):377-78. [PMID:16632302] http://dx.doi.org/10.1016/S1474-4422(06)70420-3

13. Wernig A. Weight-supported treadmill vs over-ground training for walking after acute incomplete SCI. Neurology. 2006;67(10):1900. [PMID:17130441] http://dx.doi.org/10.1212/01.wnl.0000249079.73112.38

14. Harkema SJ, Schmidt-Read M, Lorenz DJ, Edgerton VR, Behrman AL. Balance and ambulation improvements in individuals with chronic incomplete spinal cord injury using locomotor training-based rehabilitation. Arch Phys Med Rehabil. 2012;93(9):1508-17. [PMID:21777905] http://dx.doi.org/10.1016/j.apmr.2011.01.024

15. Lucareli PR, Lima MO, Lima FP, de Almeida JG, Brech GC, D'Andréa Greve JM. Gait analysis following treadmill training with body weight support versus conventional physical therapy: A prospective randomized controlled single blind study. Spinal Cord. 2011;49(9):1001-7.

[PMID:21537338] http://dx.doi.org/10.1038/sc.2011.37
16. Field-Fote EC, Roach KE. Influence of a locomotor training approach on walking speed and distance in people with chronic spinal cord injury: A randomized clinical trial. Phys Ther. 2011;91(1):48-60. [PMID:21051593] http://dx.doi.org/10.2522/ptj.20090359

17. Swinnen E, Duerinck S, Baeyens JP, Meeusen R, Kerckhofs E. Effectiveness of robot-assisted gait training in persons with spinal cord injury: A systematic review. J Rehabil Med. 2010;42(6):520-26. [PMID:20549155] http://dx.doi.org/10.2340/16501977-0538

18. Hidler J, Nichols D, Pelliccio M, Brady K, Campbell DD, Kahn JH, Hornby TG. Multicenter randomized clinical trial evaluating the effectiveness of the Lokomat in subacute stroke. Neurorehabil Neural Repair. 2009;23(1):5-13.

[PMID:19109447]

http://dx.doi.org/10.1177/1545968308326632

19. Vaney C, Gattlen B, Lugon-Moulin V, Meichtry A, Hausammann R, Foinant D, Anchisi-Bellwald AM, Palaci C, Hilfiker R. Robotic-assisted step training (lokomat) not superior to equal intensity of over-ground rehabilitation in patients with multiple sclerosis. Neurorehabil Neural Repair. 2012;26(3):212-21. [PMID:22140197] http://dx.doi.org/10.1177/1545968311425923

20. Dobkin BH, Duncan PW. Should body weight-supported treadmill training and robotic-assistive steppers for locomotor training trot back to the starting gate? Neurorehabil Neural Repair. 2012;26(4):308-17. [PMID:22412172] http://dx.doi.org/10.1177/1545968312439687

21. Pearson KG. Generating the walking gait: Role of sensory feedback. Prog Brain Res. 2004;143:123-29.

[PMID:14653157] http://dx.doi.org/10.1016/S0079-6123(03)43012-4

22. Pearson KG. Neural adaptation in the generation of rhythmic behavior. Annu Rev Physiol. 2000;62:723-53. [PMID: 10845109] http://dx.doi.org/10.1146/annurev.physiol.62.1.723

23. Kawato M. Internal models for motor control and trajectory planning. Curr Opin Neurobiol. 1999;9(6):718-27. [PMID:10607637] http://dx.doi.org/10.1016/S0959-4388(99)00028-8

24. Emken JL, Reinkensmeyer DJ. Robot-enhanced motor learning: Accelerating internal model formation during locomotion by transient dynamic amplification. IEEE Trans Neural Syst Rehabil Eng. 2005;13(1):33-39. [PMID:15813404] http://dx.doi.org/10.1109/TNSRE.2004.843173

25. Fortin K, Blanchette A, McFadyen BJ, Bouyer LJ. Effects of walking in a force field for varying durations on aftereffects and on next day performance. Exp Brain Res. 2009;199(2):145-55. [PMID:19707747] http://dx.doi.org/10.1007/s00221-009-1989-9 
26. Lam T, Anderschitz M, Dietz V. Contribution of feedback and feedforward strategies to locomotor adaptations. J Neurophysiol. 2006;95(2):766-73. [PMID:16424453] http://dx.doi.org/10.1152/jn.00473.2005

27. Lam T, Wolstenholme C, Yang JF. How do infants adapt to loading of the limb during the swing phase of stepping? J Neurophysiol. 2003;89(4):1920-28. [PMID:12611979] http://dx.doi.org/10.1152/jn.01030.2002

28. Noble JW, Prentice SD. Adaptation to unilateral change in lower limb mechanical properties during human walking. Exp Brain Res. 2006;169(4):482-95. [PMID:16328304] http://dx.doi.org/10.1007/s00221-005-0162-3

29. Pang MY, Lam T, Yang JF. Infants adapt their stepping to repeated trip-inducing stimuli. J Neurophysiol. 2003;90(4): 2731-40. [PMID:12826655] http://dx.doi.org/10.1152/jn.00407.2003

30. Houldin A, Luttin K, Lam T. Locomotor adaptations and aftereffects to resistance during walking in individuals with spinal cord injury. J Neurophysiol. 2011;106(1):247-58. [PMID:21543755] http://dx.doi.org/10.1152/jn.00753.2010

31. Lam T, Wirz M, Lünenburger L, Dietz V. Swing phase resistance enhances flexor muscle activity during treadmill locomotion in incomplete spinal cord injury. Neurorehabil Neural Repair. 2008;22(5):438-46. [PMID:18780879] http://dx.doi.org/10.1177/1545968308315595

32. Yen SC, Schmit BD, Landry JM, Roth H, Wu M. Locomotor adaptation to resistance during treadmill training transfers to overground walking in human SCI. Exp Brain Res. 2012;216(3):473-82. [PMID:22108702] http://dx.doi.org/10.1007/s00221-011-2950-2

33. Wu M, Landry JM, Schmit BD, Hornby TG, Yen SC. Robotic resistance treadmill training improves locomotor function in human spinal cord injury: A pilot study. Arch Phys Med Rehabil. 2012;93(5):782-89. [PMID:22459697] http://dx.doi.org/10.1016/j.apmr.2011.12.018

34. Pépin A, Ladouceur M, Barbeau H. Treadmill walking in incomplete spinal-cord-injured subjects: 2. Factors limiting the maximal speed. Spinal Cord. 2003;41(5):271-79. [PMID:12714989] http://dx.doi.org/10.1038/sj.sc.3101453

35. van der Salm A, Nene AV, Maxwell DJ, Veltink PH, Hermens HJ, IJzerman MJ. Gait impairments in a group of patients with incomplete spinal cord injury and their relevance regarding therapeutic approaches using functional electrical stimulation. Artif Organs. 2005;29(1):8-14. [PMID:15644078] http://dx.doi.org/10.1111/j.1525-1594.2004.29004.x

36. Ditunno J, Scivoletto G. Clinical relevance of gait research applied to clinical trials in spinal cord injury. Brain Res Bull. 2009;78(1):35-42. [PMID:18848865] http://dx.doi.org/10.1016/j.brainresbull.2008.09.003

37. Leroux A, Fung J, Barbeau H. Adaptation of the walking pattern to uphill walking in normal and spinal-cord injured subjects. Exp Brain Res. 1999;126(3):359-68.

[PMID:10382621]

http://dx.doi.org/10.1007/s002210050743

38. Ladouceur M, Barbeau H, McFadyen BJ. Kinematic adaptations of spinal cord-injured subjects during obstructed walking. Neurorehabil Neural Repair. 2003;17(1):25-31. [PMID:12645442] http://dx.doi.org/10.1177/0888439003251750

39. Lam T, Luttmann K, Houldin A, Chan C. Treadmill-based locomotor training with leg weights to enhance functional ambulation in people with chronic stroke: A pilot study. J Neurol Phys Ther. 2009;33(3):129-35. [PMID:19809391] http://dx.doi.org/10.1097/NPT.0b013e3181b57de5

40. Lam T, Pauhl K, Krassioukov A, Eng JJ. Using robotapplied resistance to augment body-weight-supported treadmill training in an individual with incomplete spinal cord injury. Phys Ther. 2011;91(1):143-51.

[PMID:21127165] http://dx.doi.org/10.2522/ptj.20100026

41. Colombo G, Joerg M, Schreier R, Dietz V. Treadmill training of paraplegic patients using a robotic orthosis. J Rehabil Res Dev. 2000;37(6):693-700. [PMID:11321005]

42. Hornby TG, Zemon DH, Campbell D. Robotic-assisted, body-weight-supported treadmill training in individuals following motor incomplete spinal cord injury. Phys Ther. 2005;85(1):52-66. [PMID:15623362]

43. Hol AT, Eng JJ, Miller WC, Sproule S, Krassioukov AV. Reliability and validity of the six-minute arm test for the evaluation of cardiovascular fitness in people with spinal cord injury. Arch Phys Med Rehabil. 2007;88(4):489-95. [PMID:17398251] http://dx.doi.org/10.1016/j.apmr.2006.12.044

44. Bolliger M, Banz R, Dietz V, Lünenburger L. Standardized voluntary force measurement in a lower extremity rehabilitation robot. J Neuroeng Rehabil. 2008;5:23.

[PMID:18957092] http://dx.doi.org/10.1186/1743-0003-5-23

45. Wirz M, Colombo G, Dietz V. Long term effects of locomotor training in spinal humans. J Neurol Neurosurg Psychiatry. 2001;71(1):93-96. [PMID:11413270] http://dx.doi.org/10.1136/jnnp.71.1.93

46. Borg G. Borg's perceived exertion and pain scales. Champaign (IL): Human Kinetics Publishers; 1998.

47. Foster C, Florhaug JA, Franklin J, Gottschall L, Hrovatin LA, Parker S, Doleshal P, Dodge C. A new approach to monitoring exercise training. J Strength Cond Res. 2001; 15(1):9-15. [PMID:11708692]

48. Musselman K, Brunton K, Lam T, Yang J. Spinal cord injury functional ambulation profile: A new measure of walking ability. Neurorehabil Neural Repair. 2011;25(3):285-93. [PMID:21357530] http://dx.doi.org/10.1177/1545968310381250 
49. van Hedel HJ, Wirz M, Dietz V. Assessing walking ability in subjects with spinal cord injury: Validity and reliability of 3 walking tests. Arch Phys Med Rehabil. 2005;86(2): 190-96. [PMID:15706542] http://dx.doi.org/10.1016/j.apmr.2004.02.010

50. Musil CM, Warner CB, Yobas PK, Jones SL. A comparison of imputation techniques for handling missing data. West $\mathbf{J}$ Nurs Res. 2002;24(7):815-29. [PMID:12428897] http://dx.doi.org/10.1177/019394502762477004

51. Musselman KE, Brunton K, Yang JF. Introducing the Spinal Cord Injury Functional Ambulation Profile (SCI-FAP): Sensitivity to change. Physiother Can. 2010;62(Suppl 1):A034.

52. Poggio T, Bizzi E. Generalization in vision and motor control. Nature. 2004;431(7010):768-74. [PMID:15483597] http://dx.doi.org/10.1038/nature03014

53. Musselman KE, Fouad K, Misiaszek JE, Yang JF. Training of walking skills overground and on the treadmill: Case series on individuals with incomplete spinal cord injury. Phys Ther. 2009;89(6):601-11. [PMID:19423643] http://dx.doi.org/10.2522/ptj.20080257

54. Jaffe DL, Brown DA, Pierson-Carey CD, Buckley EL, Lew HL. Stepping over obstacles to improve walking in individuals with poststroke hemiplegia. J Rehabil Res Dev. 2004;41(3A):283-92. [PMID:15543446] http://dx.doi.org/10.1682/JRRD.2004.03.0283

55. Huang VS, Krakauer JW. Robotic neurorehabilitation: A computational motor learning perspective. J Neuroeng Rehabil. 2009;6:5. [PMID:19243614] http://dx.doi.org/10.1186/1743-0003-6-5

56. Cai LL, Fong AJ, Otoshi CK, Liang Y, Burdick JW, Roy RR, Edgerton VR. Implications of assist-as-needed robotic step training after a complete spinal cord injury on intrinsic strategies of motor learning. J Neurosci. 2006;26(41): 10564-68. [PMID:17035542] http://dx.doi.org/10.1523/JNEUROSCI.2266-06.2006

57. Winter DA. Foot trajectory in human gait: A precise and multifactorial motor control task. Phys Ther. 1992; 72(1):45-53, discussion 54-56. [PMID:1728048]

58. McFadyen BJ, Winter DA, Allard F. Simulated control of unilateral, anticipatory locomotor adjustments during obstructed gait. Biol Cybern. 1994;72(2):151-60. [PMID:7880919] http://dx.doi.org/10.1007/BF00205979

59. Taga G. A model of the neuro-musculo-skeletal system for anticipatory adjustment of human locomotion during obstacle avoidance. Biol Cybern. 1998;78(1):9-17.

[PMID:9485584] http://dx.doi.org/10.1007/s004220050408

60. McFadyen BJ, Winter DA. Anticipatory locomotor adjustments during obstructed human walking. Neurosci Res Commun. 1991;9:37-44.
61. Lewek MD, Cruz TH, Moore JL, Roth HR, Dhaher YY, Hornby TG. Allowing intralimb kinematic variability during locomotor training poststroke improves kinematic consistency: A subgroup analysis from a randomized clinical trial. Phys Ther. 2009;89(8):829-39. [PMID:19520734] http://dx.doi.org/10.2522/ptj.20080180

62. Ziegler MD, Zhong H, Roy RR, Edgerton VR. Why variability facilitates spinal learning. J Neurosci. 2010;30(32): 10720-26. [PMID:20702702] http://dx.doi.org/10.1523/JNEUROSCI.1938-10.2010

63. Lee C, Won D, Cantoria MJ, Hamlin M, de Leon RD. Robotic assistance that encourages the generation of stepping rather than fully assisting movements is best for learning to step in spinally contused rats. J Neurophysiol. 2011;105(6):2764-71. [PMID:21430272] http://dx.doi.org/10.1152/jn.01129.2010

64. Beloozerova IN, Sirota MG. The role of the motor cortex in the control of accuracy of locomotor movements in the cat. J Physiol. 1993;461:1-25. [PMID:8350259] http://dx.doi.org/10.1113/jphysiol.1993.sp019498

65. Drew T, Jiang W, Widajewicz W. Contributions of the motor cortex to the control of the hindlimbs during locomotion in the cat. Brain Res Brain Res Rev. 2002;40(13):178-91. [PMID:12589916] http://dx.doi.org/10.1016/S0165-0173(02)00200-X

66. Widajewicz W, Kably B, Drew T. Motor cortical activity during voluntary gait modifications in the cat. II. Cells related to the hindlimbs. J Neurophysiol. 1994;72(5):207089. [PMID:7884445]

67. Camus M, Pailhous J, Bonnard M. Cognitive tuning of corticospinal excitability during human gait: Adaptation to the phase. Eur J Neurosci. 2004;20(4):1101-7.

[PMID:15305879]

http://dx.doi.org/10.1111/j.1460-9568.2004.03537.x

68. Camus M, Pailhous J, Bonnard M. On-line flexibility of the cognitive tuning of corticospinal excitability: A TMS study in human gait. Brain Res. 2006;1076(1):144-49. [PMID:16473341] http://dx.doi.org/10.1016/j.brainres.2005.12.001

69. Norton JA, Gorassini MA. Changes in cortically related intermuscular coherence accompanying improvements in locomotor skills in incomplete spinal cord injury. J Neurophysiol. 2006;95(4):2580-89. [PMID:16407422] http://dx.doi.org/10.1152/jn.01289.2005

70. Thomas SL, Gorassini MA. Increases in corticospinal tract function by treadmill training after incomplete spinal cord injury. J Neurophysiol. 2005;94(4):2844-55.

[PMID:16000519] http://dx.doi.org/10.1152/jn.00532.2005

71. Barthélemy D, Alain S, Grey MJ, Nielsen JB, Bouyer LJ. Rapid changes in corticospinal excitability during force field adaptation of human walking. Exp Brain Res. 2012; 
217(1):99-115. [PMID:22246104]

http://dx.doi.org/10.1007/s00221-011-2977-4

72. Bonnard M, Camus M, Coyle T, Pailhous J. Task-induced modulation of motor evoked potentials in upper-leg muscles during human gait: A TMS study. Eur J Neurosci. 2002;16(11):2225-30. [PMID:12473090] http://dx.doi.org/10.1046/j.1460-9568.2002.02295.x

73. Zabukovec JR, Boyd LA, Linsdell MA, Lam T. Changes in corticospinal excitability following adaptive modification to human walking. Exp Brain Res. 2013;226(4):557-64. [PMID:23494384] http://dx.doi.org/10.1007/s00221-013-3468-6

74. Petersen JA, Spiess M, Curt A, Dietz V, Schubert M; EMSCI Study Group. Spinal cord injury: One-year evolution of motor-evoked potentials and recovery of leg motor function in 255 patients. Neurorehabil Neural Repair. 2012;26(8):939-48. [PMID:22460611] http://dx.doi.org/10.1177/1545968312438437

75. Barthélemy D, Willerslev-Olsen M, Lundell H, Conway BA, Knudsen H, Biering-Sørensen F, Nielsen JB. Impaired transmission in the corticospinal tract and gait disability in spinal cord injured persons. J Neurophysiol. 2010;104(2): 1167-76. [PMID:20554839] http://dx.doi.org/10.1152/jn.00382.2010

Submitted for publication April 15, 2014. Accepted in revised form November 10, 2014.

This article and any supplementary material should be cited as follows:

Lam T, Pauhl K, Ferguson A, Malik RN, Krassioukov A, Eng JJ. Training with robot-applied resistance in people with motor-incomplete spinal cord injury: Pilot study. J Rehabil Res Dev. 2015;52(1):113-30. http://dx.doi.org/10.1682/JRRD.2014.03.0090

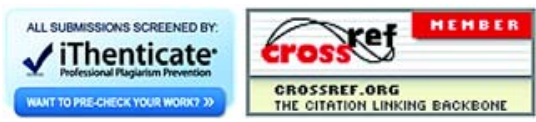


